\title{
Origin of circular collapsed landforms in the Chryse region of Mars
}

\author{
Manuel Roda ${ }^{\mathrm{a}, \mathrm{b}, *}$, Maarten G. Kleinhans ${ }^{\mathrm{b}}$, Tanja E. Zegers ${ }^{\mathrm{b}}$, Rob Govers ${ }^{\mathrm{b}}$ \\ ${ }^{a}$ Universitá degli Studi di Milano, Dipartimento di Scienze della Terra, Via Mangiagalli, 34, 20133 Milano, Italy \\ ${ }^{\mathrm{b}}$ Universiteit Utrecht, Faculty of Geosciences, Heidelberglaan 2, 3584 CS Utrecht, The Netherlands
}

\section{A R T I C L E I N F O}

\section{Article history:}

Received 29 June 2015

Revised 20 October 2015

Accepted 21 October 2015

Available online 27 October 2015

\section{Keywords:}

Geological processes

Ices

Impact processes

Mars, surface

\begin{abstract}
A B S T R A C T
The quasi-circular collapsed landforms occurring in the Chryse region of Mars share similar morphological characteristics, such as depth of collapse and polygonally fractured floors. Here, we present a statistical analysis of diameter, maximum and minimum depth, and amount of collapse of these features. Based on their morphometric characteristics, we find that these landforms have a common origin. In particular, the investigated landforms show diameter-depth correlations similar to those that impact craters of equivalent diameters exhibit. We also find that the observed amount of collapse of the collected features is strongly correlated to their diameter. Furthermore, the linear relation between minimum filling and pristine depth of craters, the constant ratio between collapse and the amount of filling and the fractured and chaotic aspect of the filling agree with melting and subsequent collapse of an ice layer below a sediment layer. This interpretation is consistent with a buried sub-ice lake scenario, which is a non-climatic mechanism for producing and storing abundant liquid water under martian conditions.
\end{abstract}

(c) 2015 Elsevier Inc. All rights reserved.

\section{Introduction}

Numerous quasi-circular collapsed features are present in the Chryse region of Mars and they share similar morphological characteristics (Fig. 1): deeply collapsed quasi-circular areas with intensively fractured floor characterized by polygonal tilted blocks very different in size (Chapman and Tanaka, 2002; Glotch and Christensen, 2005; Rodriguez et al., 2005b; Meresse et al., 2008). It has been suggested that these circular landforms originated from the collapse of buried impact craters and can occasionally merge together forming larger chaotic terrains (Sato and Kurita, 2005; Rodriguez et al., 2005a). Despite that, different classifications of these objects occur in the literature. Some of them are classified as (Fig. 1a) chaotic terrains (Carr et al., 1973; Sharp, 1973; Carr, 1980; Rotto and Tanaka, 1995) and other as (Fig. 1b) floorfractured craters (FFC, Schultz and Orphal, 1978; Korteniemi, 2003; Korteniemi et al., 2006). The third types includes circular collapsed features with fractured and broken floor within larger chaotic terrains (Fig. 1c and d). This is important, because different classifications are the basis for different explanations for their origin (see Bamberg et al. (2014) for an extensive review).

Based on their similarity with lunar FFC, Schultz and Orphal (1978) suggest uplift and fracturing of crater floor and filling sediment consequent to the rising of magma intrusion underneath

\footnotetext{
* Corresponding author at: Universitá degli Studi di Milano, Dipartimento di
} Scienze della Terra, Via Mangiagalli, 34, 20133 Milano, Italy. the crater. The high amount of collapse can be explained by the withdrawal of magma sills or by the subsidence produced after the water discharge from the melted cryosphere (Sharp, 1973; Cabrol et al., 1997; Chapman and Tanaka, 2002; Ogawa et al., 2003; Leask et al., 2006; Meresse et al., 2008). More commonly proposed scenarios are based on the increase in pressure of global aquifer with consequent disruption of the cryosphere and fracturing, followed by intensive groundwater discharge and removal of sediment by water, that would explain the collapse (Carr, 1979; Clifford, 1993; Andrews-Hanna and Phillips, 2007; Marra et al., 2014a,b). Sato et al. (2010) propose a model of earth fissuring of sediments within the crater as result of differential compaction consequent to the increase of groundwater level. The groundwater piping active below the crater floor toward the rims would be responsible for the collapse. Some authors have highlighted the role of gas hydrated dissolution and release in the collapsing process (Milton, 1974; Lambert and Chamberlain, 1978; Hoffman, 2000; Komatsu et al., 2000; Tanaka et al., 2001; Max and Clifford, 2001; Montgomery and Gillespie, 2005; Kargel et al., 2007). Warner et al. (2011) suggest a mechanism of subsurface volume loss consequent to the effusion of groundwater to the surface along linear zones of preexisting regional fractures pattern where localized deep basins can develop. Collapse over subterranean groundwater bodies appears to have played a significant role in the generation of chaotic terrains within the study region. Rodriguez et al. (2003, 2005a,b) invoked the drainage of extensive water-filled caverns in southern circum-Chryse as a major causative 

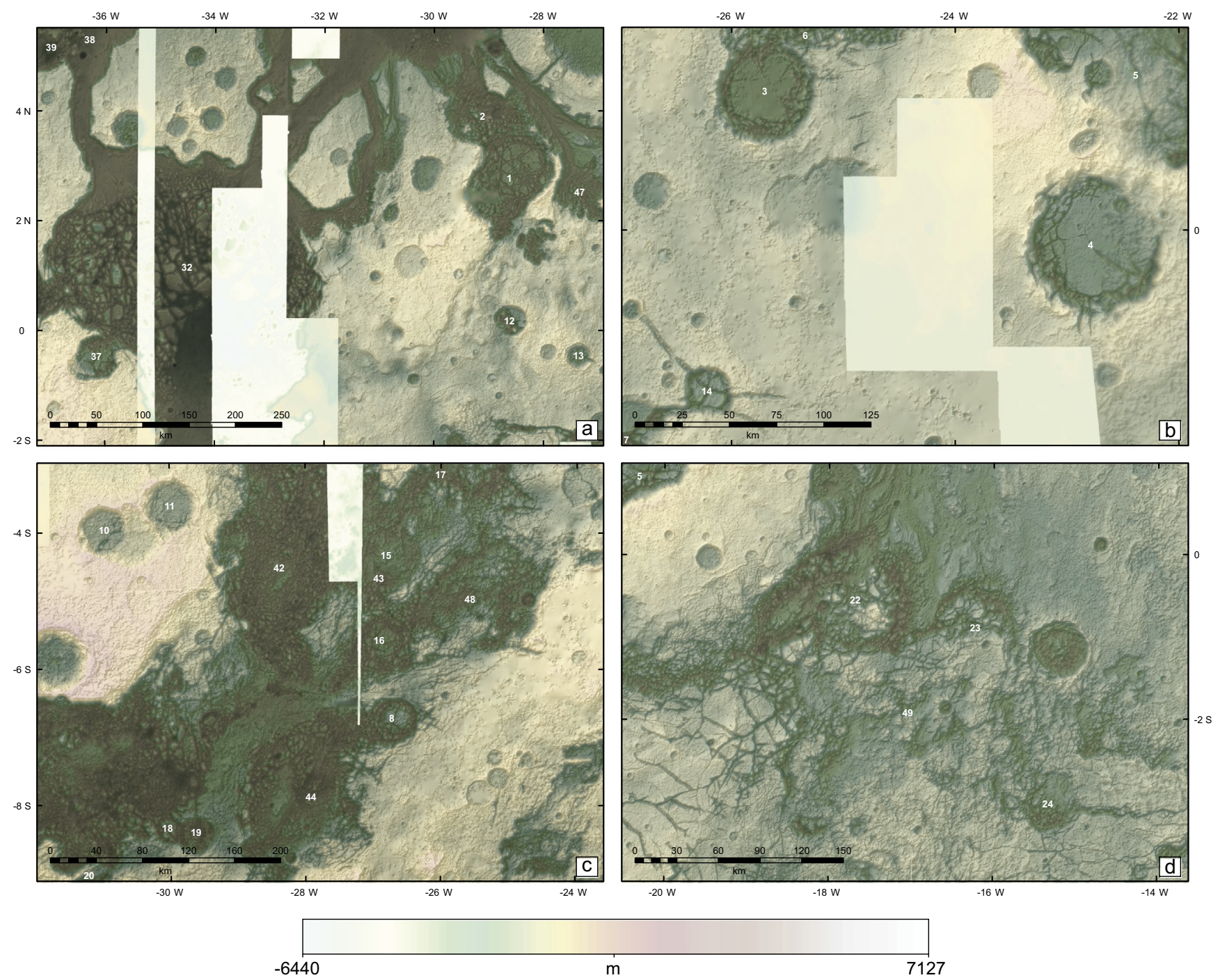

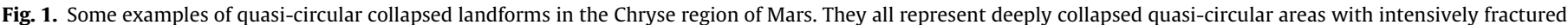

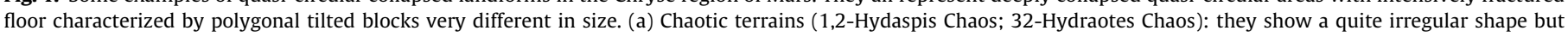

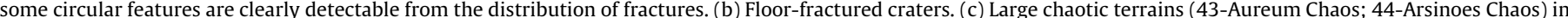

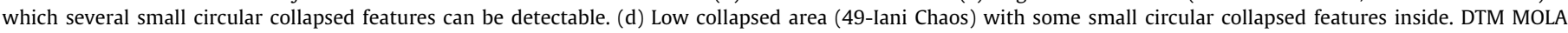
mosaic (Zuber et al., 1992) over shaded relief HRSC images (Jaumann et al., 2007).

condition leading to regional highland collapse. In subsequent investigations, Zegers et al. (2010) and Roda et al. (2014) identified geologic evidence indicative of chaos generation resulting from the collapse of sedimentary strata into underlying subsurface lakes.

Although all proposed scenarios predict fracturing and collapse, they are expected to result in very different morphometric characteristics. For example, the maximum subsidence resulting by an unrealistic complete discharge of a $20-\mathrm{km}$ deep aquifer is limited to $1.2 \mathrm{~km}$ (using a depth-porosity relation suggested by Clifford et al. (2010)). Intrusions of magma may be followed by higher collapse during the withdrawal of magma (Meresse et al., 2008). The sub-ice lake scenario requires the existence of an original crater filled with ice which drives the resulting amount and morphology of the collapse (Zegers et al., 2010; Roda et al., 2014).

In order to discern the origin and the mechanism of the evolution of the quasi-circular collapsed features we investigate whether the chaotic terrains are really different from floor-fractured craters and then which mechanism can explain the peculiar morphology of these landforms. We will first focus on their origin. We analyze the diameter, maximum depth and observed collapse of the collapsed landforms and we study their statistical relationships to evaluate whether they show common distributions and therefore a possible common origin. Next we will focus on the morphological imprint of the evolution of the crater infill. On the basis of their morphometric characteristics, we will distinguish between the formation scenarios proposed to explain the evolution of these landforms.

\section{Method}

For about fifty quasi-circular collapsed landforms around Chryse region (Fig. 2) we measure the main morphometric characteristics such as the diameter and the maximum and minimum depth with respect to the surrounding, non-collapsed area (Fig. 3). We also measure the collapse as difference between the maximum and minimum depth and it is considered as the observed collapse depth. This represents the collapse achievable. In fact the amount of collapse can be higher if the measured minimum depth is generated by collapse with respect to the surrounding areas. In this case the collapse would coincide with the maximum depth. However, the minimum depth can be only the result of pre-existing difference in topography. Since it is not 


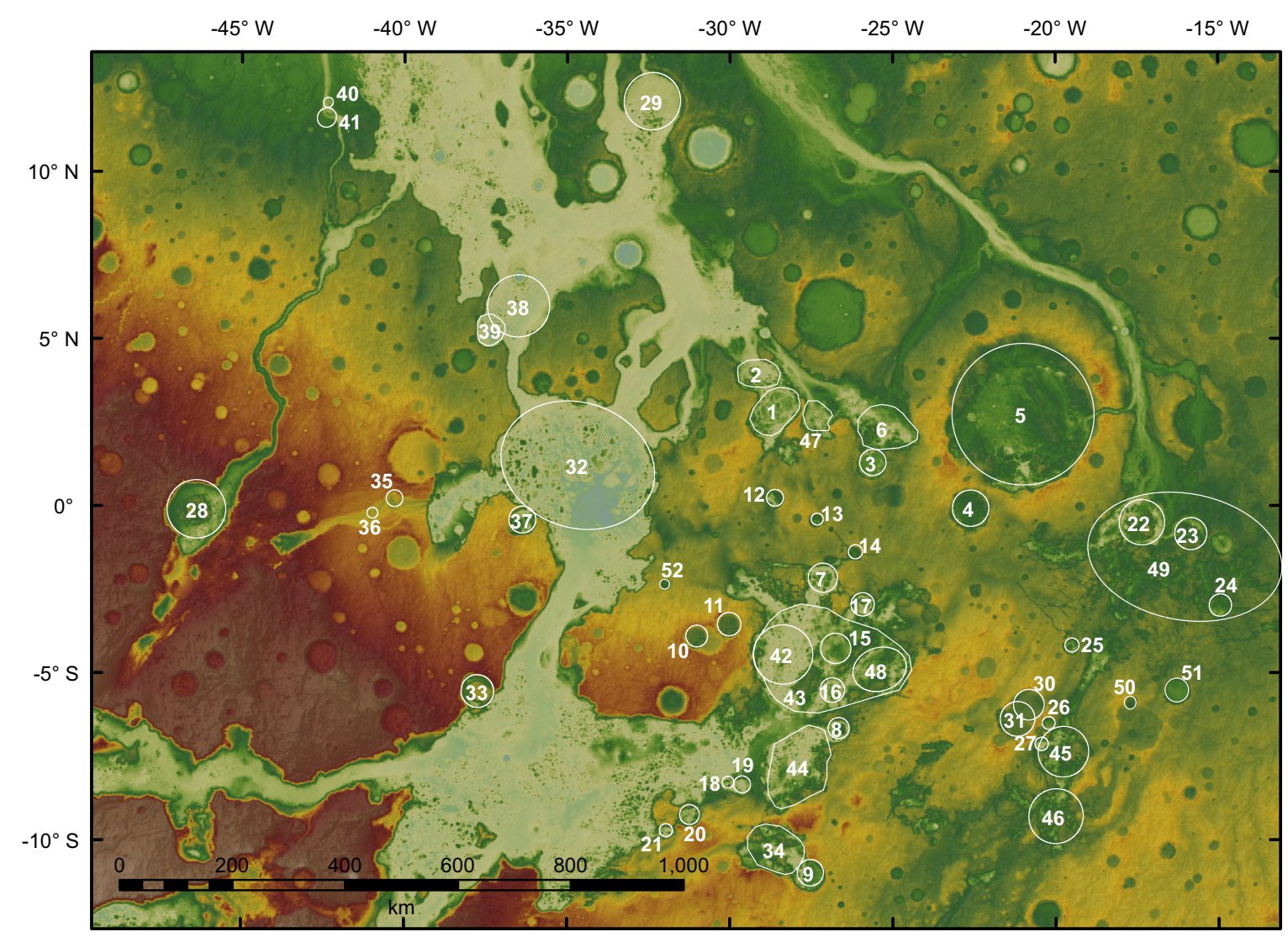

Fig. 2. Location of collected landforms around Chryse region. See Supplementary material for the reference. Elevation map based on MOLA mosaic.

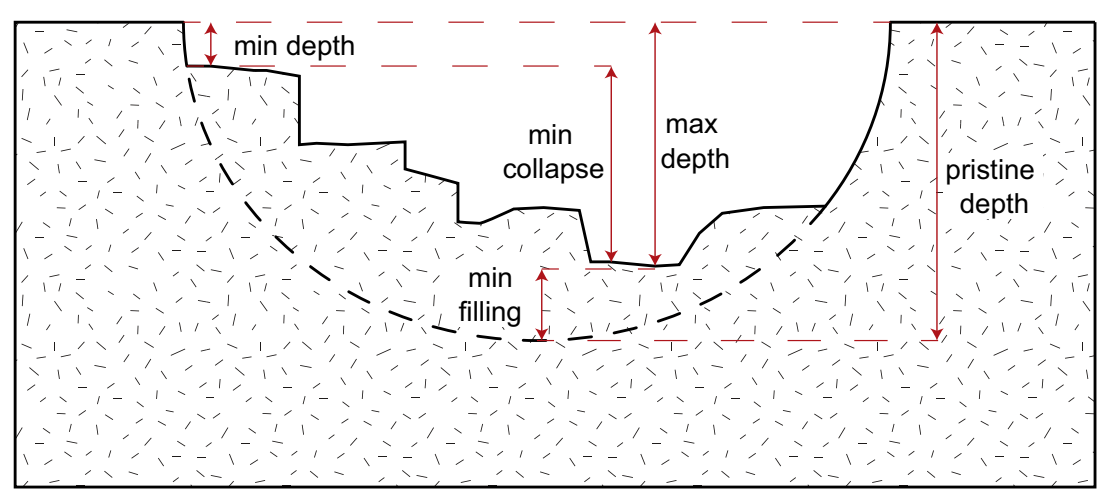

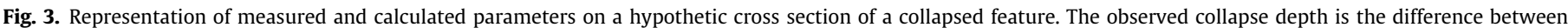

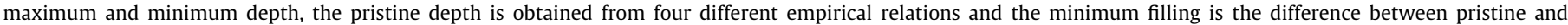
maximum depth.

possible to discriminate between the two processes, we conservatively refer to the observed collapse only. We analyze the relationships between the diameter and maximum depth and observed collapse of the measured landforms, and we compare these relations with the empirical relation between diameter and maximum depth for impact craters from different authors. Finally, on the basis of common morphometric characteristics showed by collapsed landforms, we discriminate between different evolutionary scenarios proposed for the chaotic terrains.

We combined observations from High Resolution Stereo Camera (HRSC, Jaumann et al., 2007) with Mars Orbiter Laser Alitmeter (MOLA, Zuber et al., 1992). We calculated the maximum and minimum depth of the collapsed landforms in two steps. First we made two perpendicular cross-sections across each landform and we extracted the average, maximum and minimum depths with respect to the average elevation of the surrounding area, in order to exclude the elevation of possible rims. Fig. 2 shows a hypothetic cross-section of a collapsed feature in order to represent all features shared by the circular collapsed features (collapse, fracturing and blocky floor) the morphometric characteristics we measure. Then we digitized the inner margin of each basin in ArcGIS 10, excluding the elevation of rims from the measurement, we assigned the elevation value from the average elevation of surrounding area, and we constructed a Triangulated Irregular Network (TIN) across the basin, to represent the original, pre-collapsed surface. The TIN is then converted to a raster, from which the elevation values of the base HRSC or MOLA Digital Terrain Models (DTMs) is subtracted to obtain the maximum, 
average and minimum depth of the collapsed landforms. The minimum spatial resolutions of HRSC and MOLA DTMs are respectively 70 and $400 \mathrm{~m}$ (Neumann et al., 2001; Jaumann et al., 2007; Som et al., 2008) that lead a maximum error in elevation estimates of $2 \%$ for the smallest landforms $(20 \mathrm{~km})$. Finally, the maximum and average depths obtained from cross-sections and those from the raster calculation are compared to test the accuracy. The correlation between cross-sections and calculated depths is strong, ranging between 0.8 for the average depth and 0.9 for the maximum depth (Supplementary material) and the maximum difference range between $10 \%$ for the maximum depth up to $15 \%$ for the average depth. Analyses of variance and similarity are used to test the correlation between the empirical relations for impact crater dimensions and the empirical relations for the morphometry of collapsed landforms.

\section{Results}

The circularity of the landforms is evident when the maximum and minimum diameter are compared (Fig. 4). Most of the measured landforms has a ratio between maximum and minimum diameter close to 1 , specially the smallest ones. Few landforms slightly deviate from the perfect circularity showing a rather elliptical shape $(1,2,5,6,34$ and 48). Some larger landforms show higher deviation from the perfect circularity (32, 43 and 44).

We first analyze the distribution of maximum depth and observed amount of collapse of the collected landforms with their diameter (Fig. 5). The majority of the landforms (94\%) shows a maximum depth greater than $1.2 \mathrm{~km}$ (Fig. 5a) and only the smallest landforms have a observed amount of collapse lower than $1.2 \mathrm{~km}$ (Fig. 5b). This value represents the maximum amount of collapse achievable by an unrealistic complete pore-space closure of $20 \mathrm{~km}$ thickness cryosphere after groundwater release, using a depth-porosity relation suggested by Clifford et al. (2010).

Only five landforms show a maximum depth greater than all the impact crater pristine depth best-fit lines (Fig. 5a), calculated from 4 different diameter- pristine depth relationships (Garvin et al., 2003; Boyce and Garbeil, 2007; Robbins and Hynek, 2012; Tornabene et al., 2013). Considering the uncertainties in the measurement and the scattering of the pristine depth regressions, the deviation from the empirical relations can be considered non significant. From the relation between the average depth and diameter (Fig. 5c) it is possible to distinguish two main groups of collapsed landform. The first group shows an average depth lower than $0.6-0.7 \mathrm{~km}$ while the second group has higher depths. landforms belonging to the first group have been detected in Iani Chaos and Margaritifer Chaos regions (23, 31, 45 and 49 - Fig. 2 and Supplementary material) or within outflow channels $(35,36$ and 41 - Fig. 2 and Supplementary material).

To test whether the collapsed landform can be related to impact craters we evaluate the similarity between diameter vs maximum depth and collapse relationships of the measured landforms and the empirical relations for crater dimensions, excluding those showing a maximum depth greater than the pristine depth of impact craters (Fig. 6a and b). First we determine the power-law regression for the two distributions. For the maximum depth (Fig. 6a) we obtain a power law regression characterized by a $R^{2}$ of 0.34 while a value of 0.56 is obtained for the regression of observed collapse depth (Fig. 6b). In both cases, the analysis of variance and similarity (ANOVA) gives a meaningful correlation (with significance of Fisher parameter $-F$ - respectively of $10^{-6}$ and $10^{-8}$ to not have a meaningful correlation) and the statistical error of the power-law exponent for both regressions is 6\% (Supplementary material). A similar correlation is obtained excluding

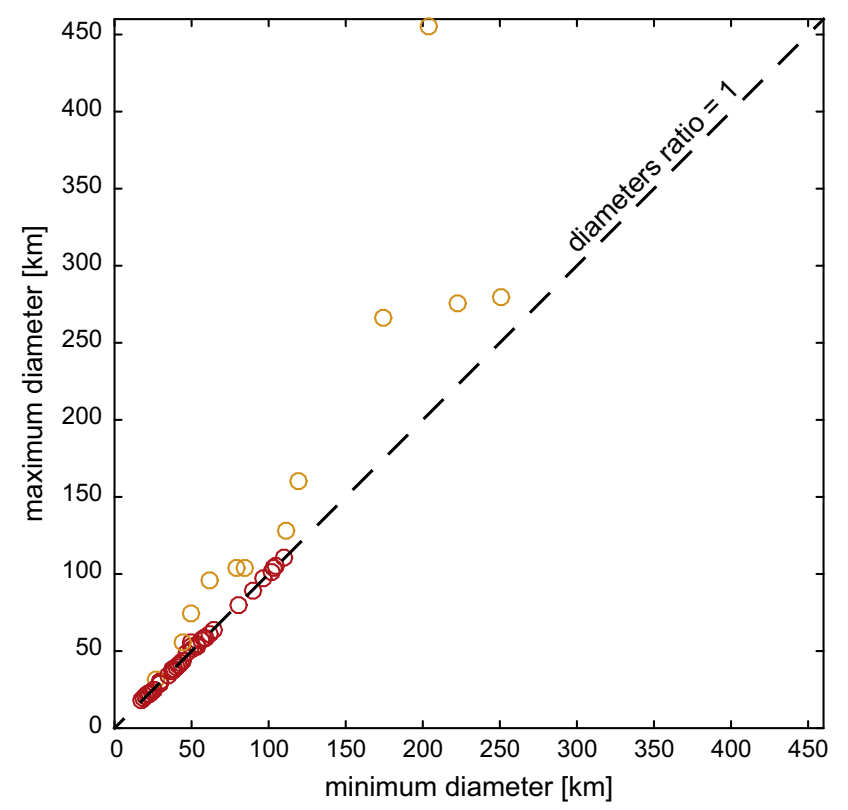

Fig. 4. Plot of showing two subsets of the investigated population of chaotic terrains. The red dots show circular features (ratio 1 in the plot), and the orange dots show chaotic terrains that deviate to various degrees from circularity as a measure of the ratio between the maximum and minimum diameters. Most of the measured landforms is circular. Few landforms show slight deviation from the circularity, specially the largest ones. (For interpretation of the references to color in this figure legend, the reader is referred to the web version of this article.)

from the regression landforms with low average depth (Fig. 6a and b - red ${ }^{1}$ crosses).

We now compare the power-law exponent of the two regressions (maximum depth and observed collapse) with the exponent of four theoretical laws of impact craters. The diameter vs maximum depth relation is statistically similar to the relationship between diameter and pristine depth of impact craters (Fig. 6a). This similarity is much more significant when the observed collapse depth achieved by chaotic terrains is taken into account. In fact, the difference in slope between the two relationships is within the statistical interpolation error (Fig. $6 \mathrm{~b}$ and Supplementary material). The same analysis excluding landforms with very low average depth (red dots) gives the same results, with some differences concerning the shifting of the intercept. This analysis confirms that the collapsed landforms can be related to impact craters. In this context, the shifting in the intercept for maximum depth relation (Fig. 6a) with respect to the pristine depth relation represents the minimum amount of sediment filling the impact crater. The amount of collapse (Fig. 6b) would represent a missing volume of material originally present beneath the sediments (likely ice or water).

To understand the evolution of crater infill, we focus on the relationship between the amount of collapse and filling with the crater size. The distribution of observed amount of collapses with the pristine depths is linear (Fig. 6c - only Tornabene et al. (2013) relation is plotted for clarity) suggesting that the amount of collapse is strongly affected by the crater dimensions. The ratio between the amount of collapse and pristine depth is 0.6. Taking into account the low sedimentation rate during Noachian and Hesperian period (Hynek and Phillips, 2001; Craddock and Howard, 2002; Kite et al., 2013), a horizontal sedimentation within

\footnotetext{
${ }^{1}$ For interpretation of color in Fig. 6, the reader is referred to the web version of
} this article. 

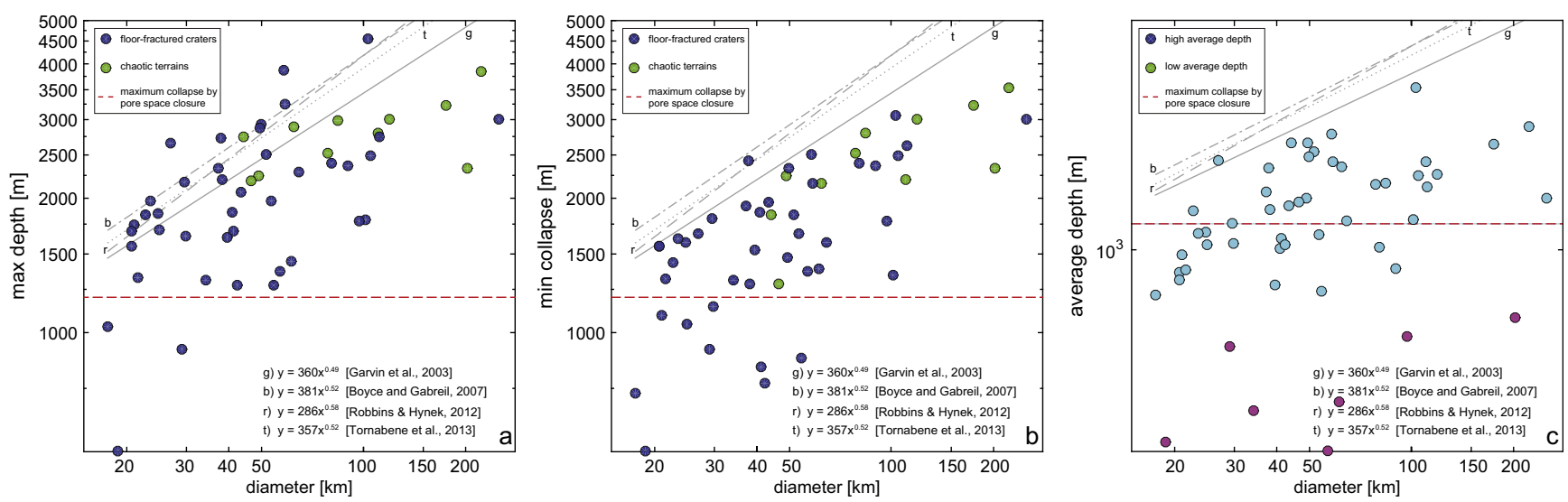

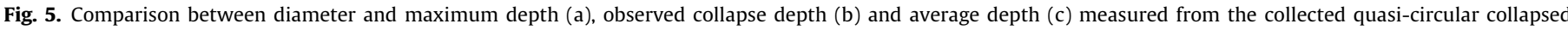

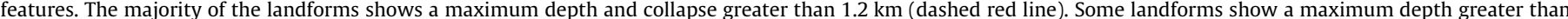

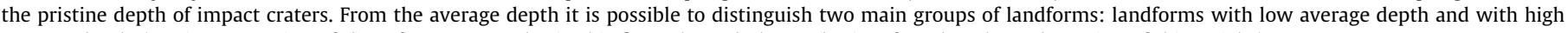
average depth. (For interpretation of the references to color in this figure legend, the reader is referred to the web version of this article.)
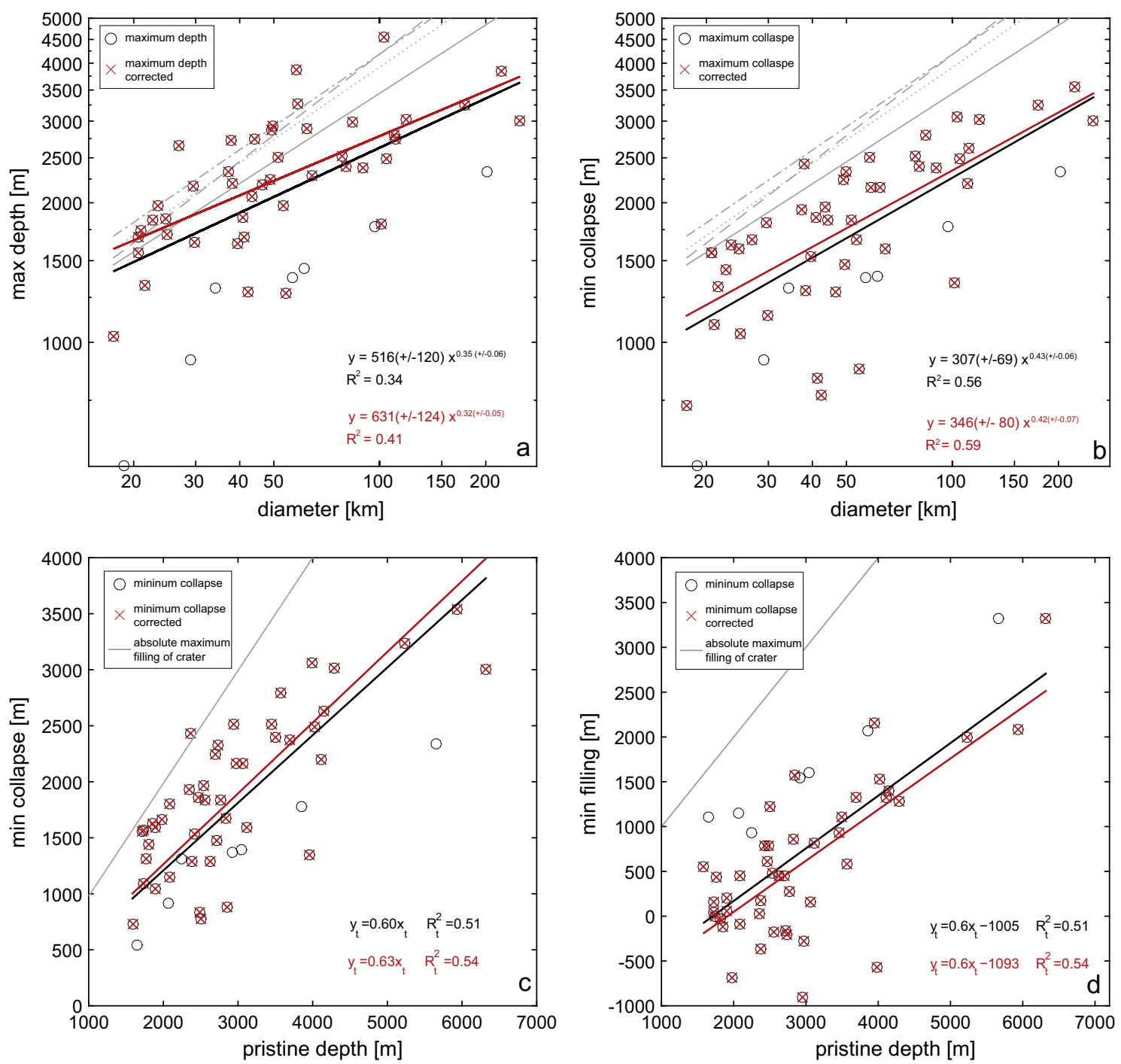

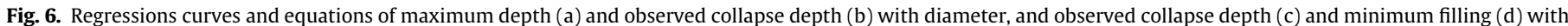

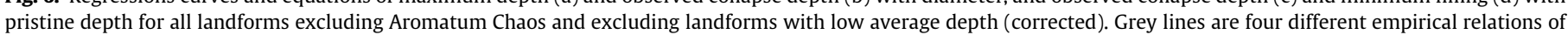

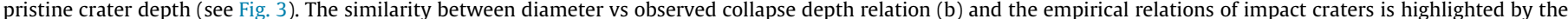

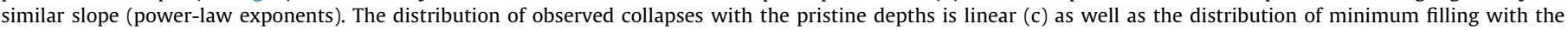
pristine depths (d). The regressions suggest a ratio between collapse and pristine depth of 0.6 . 
the crater is likely. Following this interpretation, the minimum filling achieved within the craters is the difference between the pristine and maximum depth (Fig. 3). The relation between minimum filling and pristine depth is linear (Fig. 6d).

\section{Discussion}

On the basis of morphometric properties, chaotic terrains and floor-fractured craters cannot be distinguished by peculiar characteristics or distributions and they represent similar collapsed features with a common origin. Most of the landforms has a clear circular shape. Slight deviation from the circularity (landforms 1 , $2,5,6,34$ and 48) can be explained with marginal mass-wasting related to different processes. Dewatering of fluids from gas and/ or salt hydrate buried deposits (Max and Clifford, 2001; Montgomery and Gillespie, 2005), dissolution of clathrates lenses (Kargel et al., 2007) or melting of near-surface ground ice (Costard et al., 2002) occurring around circular landforms could promote irregular scarp retreat. Even local groundwater discharge can promote an irregular shape of the collapsed landforms (Balme et al., 2006). Where the groundwater emerged on the surface, certain erosional mechanisms became active because of the seepage (Howard et al., 1988; Malin and Edgett, 2000; Luo and Howard, 2008) producing channelization, slumping, and sediment fluidization (Schorghofer et al., 2004; Marra et al., 2014a). Landslides or granular flows (Treiman, 2003) can contribute to the deviation from the circularity for the collapsed landforms. Larger deviation from the circularity occurs in larger landforms (32, 43 and 44) and can be generate by the coalescence of smaller circular landforms that can occasionally merge together forming larger chaotic terrains (Sato and Kurita, 2005; Rodriguez et al., 2005a) or by the collapse of large underground caverns proposed by Rodriguez et al. (2005a,b, 2015). In one case (49 - Iani Chaos) a very high deviation from circularity occurs and as we will see below, this can be explained differently.

The strong similarity between the relations diameter vs amount of collapse for the measured landforms, and diameter vs pristine depth for craters confirms that the collapsed features are probably related to pre-existing impact craters. The evolution of the crater infill is characterized by the high amount of collapse, indicating a large amount of volume missing (likely ice or water). The linear relations between the amount of collapse and filling with the pristine depth of craters suggest that the evolution of crater infill is strongly affected by crater size.

Taking into account these observations we can distinguish between the formation scenarios proposed to explain the evolution of the collapsed landforms. Of the major scenarios proposed to explain the evolution of the chaotic terrains, only the buried subice lake scenario matches the results of the statistical analysis. In fact, this scenario requires the existence of an original crater filled with ice, and the amount of collapse corresponds to the thickness of a buried sub-ice lake, which is strongly affected by the crater size. The maximum depth and the amount of collapse (mostly $>1.2 \mathrm{~km}$ ) are too high to be explained by aquifer discharge or gas-hydrated dissolution. In fact, the maximum subsidence resulting by an unrealistic complete discharge of a $20-\mathrm{km}$ deep aquifer is limited to $1.2 \mathrm{~km}$ (using a depth-porosity relation suggested by Clifford et al. (2010)). Pressurized groundwater outflow experiments (Marra et al., 2014b) suggest that the amount of material removed by water discharge in the outlet area is small and concentrated only along the fractures (where water is released), resulting in a very limited net subsidence at the end of the process. Furthermore, as suggested by Hanna and Phillips (2005), the break of the cryosphere by a pressurized aquifer is unlikely unless it is not taken as an a priori condition. The occurrence of a global pressurized aquifer alimented by basal melting of South polar cap is contrasted by the very low hydrostatic head between Chryse and polar regions (Russell and Head, 2007; Cassanelli et al., 2015). Source of groundwater from ice sheets on Tharsis rise can potentially generate a higher hydrostatic head (Harrison and Grimm, 2004). However, this model does not account for enough water needed to carve the outflow channels (Cassanelli et al., 2015) as well as to break the cryosphere in case of icy scenario for Mars (Forget et al., 2013; Wordsworth et al., 2013). Mechanisms based on aquifer discharge therefore cannot explain spatially extensive collapse and cryosphere fracturing. Furthermore, these scenarios are not restricted to impact craters.

The strong relation with crater size on the final collapse excludes external or regional mechanisms, such as groundwater piping or magma intrusion, as the main causes. Strong local erosion operated by pressurized groundwater release is unlikely. In fact, a random distribution of maximum depth, observed collapse and filling with crater size would be expected in this case because these parameters would be strongly related to the amount and time of water discharge. In case of magma intrusion, the amount of collapse is strongly connected to the magnitude of the driving processes, i.e., the intrusion size and the number of intrusions, and to the porosity of the magma chamber or aquifer.

Moreover, if a widespread rise of water in a regional aquifer would be responsible for the filling of craters, the same water level in all craters would be expected, resulting in a power-law relation between collapse (original crater-lake thickness) and pristine depth and a rather constant sediment thickness (crater filling). On the contrary, the linear correlation of observed collapse depth with pristine depth suggests that the original lake thickness is strictly related to the crater size, suggesting a relation between the size of impact and the release of water. The sediment thickness is also linearly related to crater depth because it represents accommodation space available after freezing of crater lake. This analysis enforces the interpretation of initial conditions leading to the shape and size of the chaotic terrains rather than regional processes. Furthermore, the statistical relations suggest that one single process can be the main cause for the origin of all circular collapsed features instead of a host of local mechanisms for each case.

These observations lead to the following scenario for the chaotic terrains (Fig. 7). After the formation of an impact crater the increase in temperature resulting from the release of impact energy would induce melting of the surrounding cryosphere (Newsom et al., 1996; Segura et al., 2002; Abramov and Kring, 2005; Barnhart et al., 2010). The generated groundwater flows towards the crater, which represents a topographically depressed area with low hydraulic head and produces a crater-lake (Newsom et al., 1996; Rathbun and Squyres, 2002; Abramov and Kring, 2005). The volume of molten cryosphere and the amount of water flow is strictly related to the size of the impact crater (Segura et al., 2002, 2008): in fact larger craters result in more shock heating of the cryosphere, more melting and, therefore, a larger and deeper lake. Alternatively crater-lake can be formed as a consequence of the retreat of Oceanus Borealis during the Late Noachian as suggested by Rodriguez et al. (2015). Due to low surface temperatures, the water lake freezes (McKay et al., 1985; Roda et al., 2014) and sediments can be deposited at the top of the ice layer. The buried ice unit melts as a result of the thermal insulation by the overburden in combination with the planetary heat loss, creating a subsurface lake. The system is no longer stable and the overburden collapses, resulting in massive expulsion of liquid water to the surface (Zegers et al., 2010; Roda et al., 2014). Taking into account a uniformly distributed heat loss, the amount of melting is strictly affected by the crater size. This scenario is consistent with the late stage of the scenario proposed by Rodriguez et al. 


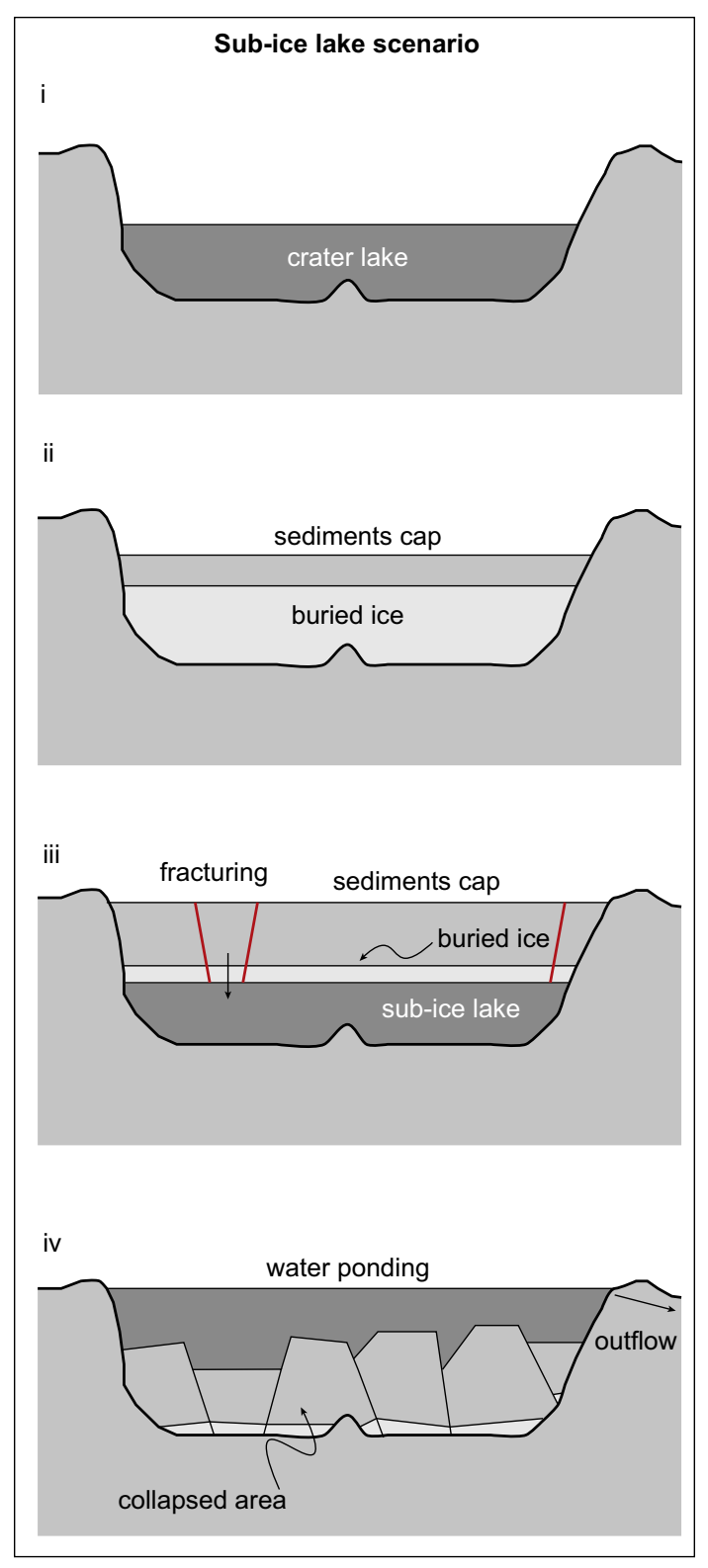

Fig. 7. Sketch of the different stages of the buried sub-ice lake scenario. After the formation of the impact crater a crater lake is generated as result of melting of the surrounding cryosphere (i). Due to low surface temperatures, the water lake freezes and sediments can be depositated at the top of the ice layer (ii). The combined effect of thermal insulation by the sediment cover and planetary heat loss induces melting of the ice layer (iii), large scale collapse of sediment cap with consequent water outflow (iv) (redrawn after Roda et al. (2014)). (For interpretation of the references to color in this figure legend, the reader is referred to the web version of this article.)

(2015), in which buried ice saturated deposits and ice-lakes, frozen after the retreating of the primordial ocean during the Late Noachian, melt allowing the collapse of irregular cavernous systems and circular collapsed features.

From the analysis of the average depth two main groups can be distinguished. Landforms collected in Iani Chaos and Margaritifer Chaos regions or within outflow channels belong to the first group, with a low average depth. They show relatively high maximum depth and collapse in contrast with the low average depth, but localized in small areas. Even the shape of these landform is very irregular with a strong deviation from the circularity. These observations are consistent with a mechanism of subsurface volume loss as a result of the effusion of groundwater to the surface, and development of deeper basins localized along linear zones of preexisting regional pattern of fractures (Warner et al., 2011). This can explain the general low amount of collapse, with some areas showing higher maximum depth and the strong deviation from circularity. In the second group, the collapsed features are generated within outflow channels and show low maximum depth, collapse and average depth. A secondary evolution of these landforms has been proposed by Rodriguez et al. (2005a, 2011): the limited collapse of these landforms may be the result of liquid volume loss from lenses of volatiles (e.g. liquid briny fluids) exhumed after the carving of outflow channels and their dissection (secondary chaos). They may also be pits formed by pressurized groundwater outflow (Marra et al., 2014b). Both scenarios are consistent with the low collapse shown by these landforms. Larger chaotic terrains (e.g. 32, 43 and 44) can be formed in regions of dense overlapping impact craters (Rodriguez et al., 2005a).

The initial evolution stages of quasi-circular collapsed features (chaotic terrains and floor-fractured craters) are strictly related to initial conditions, such as the size of impact craters and the amount of water ice in the surrounding cryosphere. In the subsequent steps, a global mechanism may have been responsible for the ice melting and the collapse of sediments. These results are consistent with the scenario of collapsed underground caverns proposed by Rodriguez et al. (2005a,b) and in agreement with a buried sub-ice lake the scenario proposed Zegers et al. (2010) and Roda et al. (2014). Global climate change is not required to develop a sub-ice lake scenario, and large amount of liquid water can be generated by a mechanism unrelated to climate, in agreement with Forget et al. (2013) and Wordsworth et al. (2013) who highlight that the early martian climate was too cold to allow long-term surface liquid water, and a non-climatic mechanism must occur to explain the highly erosive structures on Mars. Larger chaotic terrains may result from the merging of several circular collapses. A few chaotic terrains may have been generated as secondary chaos, after outflow channel carving, or by groundwater effusion, likely driven by a regional pattern of fractures (Rodriguez et al., 2005a, 2011). In both cases, the average collapse is low and clearly distinguishable from the highly collapsed chaos.

Although the intent of this paper is to suggest an alternative mechanism for the sole circular collapsed landforms we may speculate about the consequence of this scenario. The highly depressed area formed by a collapse scenario may represent a preferential way to discharge water from the aquifer, leading the formation of the outflow channels that very often have been headed by chaotic terrains. In this scenario the pressure of the confined aquifer can be lower than the strength of the cryosphere allowing remarkable water discharge even for limited hydrostatic head or relative small compartmented aquifer.

\section{Conclusions}

We analyzed the morphometric characteristics of several quasi-circular collapsed features around Chryse region in order to understand whether the chaotic terrains are really different from floor-fractured craters and to distinguish between the possible formation scenarios proposed for these features. Chaotic terrains and floor-fractured craters cannot be distinguished by specific morphometric characteristics or distributions and they have similar origin. The high average depth shown by the quasi-circular collapsed features in Chryse region and the strong correlation between collapse and pristine depth strongly support their formation in older impact craters. The strong relation between the amount of collapse and the size of craters suggest that a local mechanism was responsible for the formation of the collapsed landforms. The resulting 
morphology agrees with a buried sub-ice lake scenario proposed to explain the evolution of martian chaotic terrains.

\section{Acknowledgments}

Netherlands Organization for Scientific Research (NWO) and Netherlands Space Office (NSO grant) are gratefully acknowledged. We thank Andrea Crugnola, Fabrizio Tavecchio, Wouter A. Marra and Tjalling T. de Haas for comments and stimulating discussions. We gratefully acknowledge J. Alexis Palmero Rodriguez, Matt Balme, Stephen M. Clifford, the reviewer M.A. de Pablo and the anonymous reviewer for their highly constructive criticism of the text. The authors contributed in the following proportions to conception and design, modeling, analysis and conclusions, manuscript preparation and project acquisition (\%): $\operatorname{MR}(70,90,50,60,0)$; $\operatorname{MGK}(10,10,25,30,0) ; \operatorname{TEZ}(10,0,0,0,90) ; \operatorname{RG}(10,0,25,10,10)$.

\section{Appendix A. Supplementary material}

Supplementary data associated with this article can be found, in the online version, at http://dx.doi.org/10.1016/j.icarus.2015.10. 020.

\section{References}

Abramov, O., Kring, D.A., 2005. Impact-induced hydrothermal activity on early Mars. J. Geophys. Res. 110 (E12), 1-19.

Andrews-Hanna, J.C., Phillips, R.J., 2007. Hydrological modeling of outflow channels and chaos regions on Mars. J. Geophys. Res. 112 (E8), 1-14.

Balme, M. et al., 2006. Orientation and distribution of recent gullies in the southern hemisphere of Mars: Observations from High Resolution Stereo Camera/Mars Express (HRSC/MEX) and Mars Orbiter Camera/Mars Global Surveyor (MOC MGS) data. J. Geophys. Res.: Planets 111 (E5), 1-20.

Bamberg, M. et al., 2014. Floor-fractured craters on Mars - Observations and origin. Planet. Space Sci. 98, 146-162.

Barnhart, C.J., Nimmo, F., Travis, B.J., 2010. Martian post-impact hydrotherma systems incorporating freezing. Icarus 208 (1), 101-117.

Boyce, J.M., Garbeil, H., 2007. Geometric relationships of pristine martian complex impact craters, and their implications to Mars geologic history. Geophys. Res. Lett. 34 (16), 1-5.

Cabrol, N.A., Grin, E.A., Dawidowicz, G., 1997. A model of outflow generation by hydrothermal underpressure drainage in volcano-tectonic environment, Shalbatana Vallis (Mars). Icarus 125 (2), 455-464.

Carr, M.H., 1979. Formation of martian flood features by release of water from confined aquifers. J. Geophys. Res. 84 (6), 2995-3007.

Carr, M.H., 1980. Morphology of the martian surface. Space Sci. Rev. 25 (3), 231 284.

Carr, M.H., Masursky, H., Saunders, R.S., 1973. A generalized geologic map of Mars. J Geophys. Res. 78 (20), 4031-4036.

Cassanelli, J.P., Head, J.W., Fastook, J.L., 2015. Sources of water for the outflow channels on Mars: Implications of the Late Noachian "icy highlands" model for melting and groundwater recharge on the Tharsis rise. Planet. Space Sci. 108 54-65.

Chapman, M., Tanaka, K., 2002. Related magma-ice interactions: Possible origins of chasmata, chaos, and surface materials in Xanthe, Margaritifer, and Meridian Terrae, Mars. Icarus 155 (2), 324-339.

Clifford, S.M., 1993. A model for the hydrologic and climatic behavior of water on Mars. J. Geophys. Res. 98 (E6), 10973-11016.

Clifford, S.M. et al., 2010. Depth of the martian cryosphere: Revised estimates and implications for the existence and detection of subpermafrost groundwater. J. Geophys. Res. 115 (E7), 1-17.

Costard, F. et al., 2002. Formation of recent martian debris flows by melting of nearsurface ground ice at high obliquity. Science 295 (5552), 110-113.

Craddock, R.A., Howard, A.D., 2002. The case for rainfall on a warm, wet early Mars. J. Geophys. Res.: Planets 107 (E11), 1-36.

Forget, F. et al., 2013. 3D modelling of the early martian climate under a denser $\mathrm{CO}_{2}$ atmosphere: Temperatures and $\mathrm{CO}_{2}$ ice clouds. Icarus 222 (1), 81-99.

Garvin, B., Sakimoto, S.E.H., Frawley, J.J., 2003. Craters on Mars: Global geometric properties from gridded MOLA topography. In: Sixth International Conference on Mars. Pasadena, California, p. 3277.

Glotch, T., Christensen, P., 2005. Geologic and mineralogic mapping of Aram Chaos: Evidence for a water-rich history. J. Geophys. Res. 110 E09006.

Hanna, J.C., Phillips, R.J., 2005. Hydrological modeling of the martian crust with application to the pressurization of aquifers. J. Geophys. Res. 110 (E1), 1-19.

Harrison, K.P., Grimm, R.E., 2004. Tharsis recharge: A source of groundwater for martian outflow channels. Geophys. Res. Lett. 31 (14), 1-4.

Hoffman, N., 2000. White Mars: A new model for Mars' surface and atmosphere based on $\mathrm{CO}_{2}$. Icarus 146 (2), 326-342.
Howard, A.D., McLane, Charles F., 1988. Erosion of cohesionless sediment by groundwater seepage. Water Resour. Res. 24 (10), 1659-1674.

Hynek, B., Phillips, R., 2001. Evidence for extensive denudation of the martian highlands. Geology 29 (5), 407-410.

Jaumann, R. et al., 2007. The high-resolution stereo camera (HRSC) experiment on Mars Express: Instrument aspects and experiment conduct from interplanetary cruise through the nominal mission. Planet. Space Sci. 55 (7-8), 928-952.

Kargel, J.S. et al., 2007. Martian hydrogeology sustained by thermally insulating gas and salt hydrates. Geology 35 (11), 975-978.

Kite, E.S., Lucas, A., Fassett, C.I., 2013. Pacing early Mars fluvial activity at Aeolis Dorsa: Implications for Mars Science Laboratory observations at Gale Crater and Aeolis Mons. Icarus 225, 850-855.

Komatsu, G. et al., 2000. A chaotic terrain formation hypothesis: Explosive outgas and outflow by dissociation of clathrate on Mars. In: Lunar Planetary Science Conference XXXI. Lunar and Planetary Institute, Houston, p. 1434.

Korteniemi, J., 2003. Collapses and depressions post-dating crater formation in martian impact structures - Distribution and consequences. In: 3rd International conference on large meteorite impacts. Nördlingen, Germany, p. 4091.

Korteniemi, J. et al., 2006. Floor-fractured craters on the terrestrial planets - The martian perspective. In: Wilson, A. (Ed.), Proceedings of the first International Conference on Impact Cratering in the Solar System. ESA Publications Division, Noordwijk, The Netherlands, p. 2145.

Lambert, R.J., Chamberlain, V., 1978. $\mathrm{CO}_{2}$ permafrost and martian topography. Icarus 34 (3), 568-580.

Leask, H.J., Wilson, L., Mitchell, K.L., 2006. Formation of Aromatum Chaos, Mars: Morphological development as a result of volcano-ice interactions. J. Geophys. Res. 111, 1-16.

Luo, W., Howard, A.D., 2008. Computer simulation of the role of groundwater seepage in forming martian valley networks. J. Geophys. Res. 113 (E5) (05) E05002.

Malin, M.C., Edgett, K.S., 2000. Evidence for recent groundwater seepage and surface runoff on Mars. Science 288 (5475), 2330-2335.

Marra, W.A. et al., 2014a. Valley formation by groundwater seepage, pressurized groundwater outbursts and crater-lake overflow in flume experiments with implications for Mars. Icarus 232, 97-117.

Marra, W.A. et al., 2014b. Pressurized groundwater outflow experiments and numerical modeling for outflow channels on Mars. J. Geophys. Res.: Planets, 2668-2693.

Max, M., Clifford, S., 2001. Initiation of martian outflow channels: Related to the dissociation of gas hydrate? Geophys. Res. Lett. 28 (9), 1787-1790.

McKay, C. et al., 1985. Thickness of ice on perennially frozen lakes. Nature 313, 561562.

Meresse, S. et al., 2008. Formation and evolution of the chaotic terrains by subsidence and magmatism: Hydrates Chaos, Mars. Icarus 194 (2), 487-500.

Milton, D.J., 1974. Carbon dioxide hydrate and floods on Mars. Science 183 (4125), 654-656.

Montgomery, D., Gillespie, A., 2005. Formation of martian outflow channels by catastrophic dewatering of evaporite deposits. Geology 33 (8), 625-628.

Neumann, G.A. et al., 2001. Crossover analysis of Mars orbiter laser altimeter data. J. Geophys. Res.: Planets 106 (E10), 23753-23768.

Newsom, H. et al., 1996. Impact crater lakes on Mars. J. Geophys. Res. 101 (E6), $14951-14955$

Ogawa, Y., Yamagishi, Y., Kurita, K., 2003. Evaluation of melting process of the permafrost on Mars: Its implication for surface features. J. Geophys. Res. 108, 1 12.

Rathbun, J.A., Squyres, S.W., 2002. Hydrothermal systems associated with martian impact craters. Icarus 157 (2), 362-372.

Robbins, S.J., Hynek, B.M., 2012. A new global database of Mars impact craters $\geqslant 1 \mathrm{~km}$ : 2. Global crater properties and regional variations of the simple-tocomplex transition diameter. J. Geophys. Res.: Planets 117 (E6), 1-21.

Roda, M. et al., 2014. Catastrophic ice lake collapse in Aram Chaos, Mars. Icarus 236, 104-121.

Rodriguez, J.A.P. et al., 2005a. Control of impact crater fracture systems on subsurface hydrology, ground subsidence, and collapse, Mars. J. Geophys. Res.-Planets 110 (E6), 1-22.

Rodriguez, J.A.P. et al., 2005b. Outflow channel sources, reactivation, and chaos formation, Xanthe Terra, Mars. Icarus 175 (1), 37-57.

Rodriguez, J.A.P. et al., 2011. Secondary chaotic terrain formation in the higher outflow channels of southern circum-Chryse, Mars. Icarus 213 (1), 150-194.

Rodriguez, J.A.P., Sasaki, S., Miyamoto, H., 2003. Nature and hydrological relevance of the Shalbatana complex underground cavernous system. Geophys. Res. Lett. 30 (6), 1-4.

Rodriguez, J.A.P. et al., 2015. Martian outflow channels: How did their source aquifers form, and why did they drain so rapidly? Scientific Reports 5, $13404 \mathrm{EP}$

Rotto, S., Tanaka, K.L., 1995. Geologic/geomorphic map of the Chryse Planitia Region of Mars $(1: 5,000,000)$. In: Miscellaneous Investigations Series Map. Department of the Interior - United States Geological Survey.

Russell, P.S., Head, J.W., 2007. The martian hydrologic system: Multiple recharge centers at large volcanic provinces and the contribution of snowmelt to outflow channel activity. Planet. Space Sci. 55 (3), 315-332.

Sato, H., Kurita, K., 2005. Circular collapsed features related to the chaotic terrain formation on Mars. In: Lunar and Planetary Science Conference. 36, Houston, TX, USA, p. 2248.

Sato, H., Kurita, K., Baratoux, D., 2010. The formation of floor-fractured craters in Xanthe Terra. Icarus 207 (1), 248-264. 
Schorghofer, N. et al., 2004. Spontaneous channelization in permeable ground: Theory, experiment, and observation. J. Fluid Mech. 503, 357-374.

Schultz, P.H., Orphal, D.L., 1978. Floor-fractured craters on the Moon and Mars. Meteoritics 13, 622-625.

Segura, T.L. et al., 2002. Environmental effects of large impacts on Mars. Science 298 (5600), 1977-1980.

Segura, T.L., Toon, O.B., Colaprete, A., 2008. Modeling the environmental effects of moderate-sized impacts on Mars. J. Geophys. Res.: Planets 113, 1-15.

Sharp, R.P., 1973. Mars - Fretted and chaotic terrains. J. Geophys. Res. 78 (20), 4073-4083.

Som, S.M., Greenberg, H.M., Montgomery, D.R., 2008. The Mars Orbiter Laser Altimeter dataset: Limitations and improvements. Mars 4, 14-26.

Tanaka, K.L. et al., 2001. Huge, $\mathrm{CO}_{2}$-charged debris-flow deposit and tectonic sagging in the northern plains of Mars. Geology 29 (5), 427-430.
Tornabene, L.L. et al., 2013. A revised global depth-diameter scaling relationship for Mars based on pitted impact melt-bearing craters. In: 44th Lunar and Planetary Science Conference, p. 2592.

Treiman, A.H., 2003. Geologic settings of martian gullies: Implications for their origins. J. Geophys. Res.: Planets 108 (E4), 1-13.

Warner, N.H. et al., 2011. Constraints on the origin and evolution of Iani Chaos, Mars. J. Geophys. Res. 116 (E6), 1-29.

Wordsworth, R. et al., 2013. Global modelling of the early martian climate under a denser $\mathrm{CO}_{2}$ atmosphere: Water cycle and ice evolution. Icarus 222 (1), 1-19.

Zegers, T.E. et al., 2010. Melt and collapse of buried water ice: An alternative hypothesis for the formation of chaotic terrains on Mars. Earth Planet. Sci. Lett. 297 (3-4), 496-504.

Zuber, M.T. et al., 1992. The Mars Observer laser altimeter investigation. J. Geophys. Res.: Planets 97 (E5), 7781-7797. 